\title{
Cuidados Adotados pela Equipe de Enfermagem Diante de Clientes Mastectomizadas: Revisão de Literatura
}

SANTOS, Cristina do Socorro Costa Levy ${ }^{[1]}$, AZEVEDO, Vitória Augusta Machado de ${ }^{[2]}$, MOREIRA,

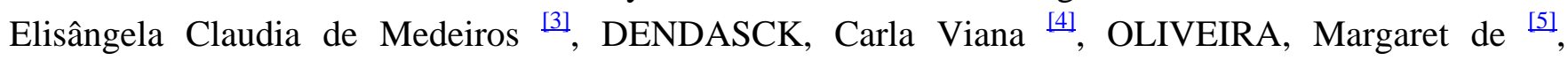
OLIVEIRA, Euzébio de [6]

SANTOS, Cristina do Socorro Costa Levy; et.al. Cuidados Adotados pela Equipe de Enfermagem Diante de Clientes Mastectomizadas: Revisão de Literatura. Revista Científica Multidisciplinar Núcleo do Conhecimento. Ed. 11. Ano 02, Vol. 04. pp 84-95, Novembro de 2017. ISSN:2448-0959, Link de acesso: https://www.nucleodoconhecimento.com.br/saude/mastectomizadas, DOI; 10.32749/nucleodoconhecimento.com.br/saude/mastectomizadas

\section{RESUMO}

Os cuidados adotados pela equipe de enfermagem diante de clientes mastectomizadas é objeto de estudo de suma importância para o atendimento dessas pacientes. Para objetivou-se identificar, na literatura, os cuidados adotados pela equipe de enfermagem diante de clientes mastectomizadas. Procedeu-se o levantamento eletrônico por meio do portal de Pesquisa da Biblioteca Virtual em Saúde (BVS), nas bases de dados: Medline, Lilacs, Ibecs, Scielo, BDEnf, Biblioteca Cochrane, entre outras bases desse portal, utilizando as palavras chave: enfermagem, cuidados de enfermagem, mastectomia, neoplasias da mama, enfrentamento, reabilitação, autocuidado, publicados de 2009 a 2013. A amostra constituiu-se de sete artigos. Dos artigos selecionados $100 \%$ relatam a importância da mulher receber informações a respeito dos cuidados no período perioperatório que se divide em pré-operatório, trans-operatório e pósoperatório; 90\% abordam o cuidado de enfermagem à mulher com diagnóstico de câncer de mama e provável evolução a mastectomia; e, 40\% dos artigos abordam o impacto psicológico, social e físico bem como a aceitação à mutilação. Os artigos destacam o papel educador do enfermeiro na assistência prestada a estas mulheres, já que a falta ou imprecisão nas informações prestadas favorece a ocorrência de complicações. O enfermeiro é o profissional preparado para desempenhar este papel de educador, fornecendo informações para a paciente e seus familiares, o que está destacado no Código de Ética dos Profissionais de Enfermagem Brasileiros. Além disso, a enfermagem deve promover a articulação com as demais áreas da saúde, com ações que contribuam para uma vida de qualidade bem como para sua reinserção social. 
Palavras-chave: Enfermagem, Cuidados de Enfermagem, Mastectomia, Neoplasias da Mama, Enfrentamento, Reabilitação, Autocuidado.

\section{INTRODUÇÃO}

A neoplasia mamária maligna é a patologia que mais aterroriza as mulheres, devido à sua elevada taxa de incidência e, suas consequências psicossociais. Sendo a que mais acomete as mulheres no mundo, tanto nos países desenvolvidos quanto em desenvolvimento, tendo a maior mortalidade nos países em desenvolvimento (INSTITUTO NACIONAL DO CÂNCER, 2014).

Segundo o INCA (2014), atualmente no Brasil, são esperados 57.129 casos novos de carcinomas mamários, possuindo um risco estimado de 56,09 casos a cada 100 mil mulheres. Na região Norte, é o segundo tumor de maior incidência acometendo 21,29/100 mil mulheres, sendo que para o Estado do Pará a estimativa para 2014 são de 21.17/100 mil mulheres e para Capital do Estado, Belém, a estimativa é de 46,78/100 mil mulheres de casos novos, nos últimos anos a taxa de mortalidade por câncer no Brasil tem tido um aumento crescente, é um indicador que a doença ainda é diagnosticada tardiamente.

O surgimento de uma neoplasia maligna decorre da interação de fatores genéticos e ambientais, dentre os quais se destacam: história familiar, idade superior a 40 anos, sexo feminino, exposição à radiação, nutrição, tabagismo, etilismo, obesidade, primeira menstruação precoce, menopausa tardia (após os 50 anos), primeira gravidez após os 30 anos (SOUZA et al., 2013).

Segundo Smeltzer e Bare (2002) a neoplasia mamária pode ocorrer em qualquer parte da mama, mas a maioria surge no quadrante superior externo, onde há maior parte do tecido mamário. Em geral, as lesões são insensíveis, fixas e rijas com bordas irregulares.

A abordagem terapêutica é composta basicamente pela cirurgia e terapias adjuvantes como a quimioterapia, radioterapia e hormonioterapia. A principal abordagem cirúrgica é a mastectomia, que consiste em um procedimento cirúrgico onde ocorre a retirada total da mama, ocasionando restrições físicas, que diminuem a capacidade do movimento corporal, afetando o desempenho sexual e social da mulher (ANGERAMI-CAMON; GASPAR, 2013).

Segundo Azevedo e Lopes (2006) após a cirurgia de retirada da mama, a mulher vivencia um processo de aceitação, de conformação com a condição de ser mastectomizada e com as mudanças ocorridas no próprio corpo, constituindo-se em um processo de elaboração de mecanismos para aceitação do corpo modificado. A cirurgia não afeta apenas a mastectomizada, mas todos a sua volta como: família, grupo de amigos, potencializando-se com a indicação dos tratamentos associados (radioterapia, quimioterapia) à cirurgia.

Assim, é importante que a equipe multiprofissional que acompanha a paciente identifique suas ansiedades, preocupações, anseios e medos ajudando-a a enfrenta-los.

Neste contexto a equipe de enfermagem é a que está diretamente ligada a paciente, e encontra respaldo na visita pré-operatória para fornecer informações que contemplem todas as ações a serem desenvolvidas no pré, trans e pós-operatório (BITTENCOURT; CADETE, 2002). As atividades da enfermagem, durante esse tempo, incluem cuidados técnicos baseados em dados obtidos por meio das informações do 
prontuário, da observação e da entrevista pré-operatória.

A mulher deverá receber informações a respeito dos cuidados após a cirurgia, orientações e informações sobre as diferentes etapas de recuperação, de como será realizada a cirurgia, cuidados com o braço, exercícios que recuperem a capacidade funcional do braço e ombro, além de informações sobre outros tratamentos como radioterapia, quimioterapia e hormonioterapia. Por meio da comunicação a equipe de enfermagem deve ajudar a mastectomizada a conceituar seus problemas, atribuir significados aos acontecimentos em sua vida e principalmente buscar alternativas de soluções (ALVES, 2011; BARRETO et al., 2008; MOURÃO, 2011).

Assim, o tema cuidados adotados pela equipe de enfermagem diante de clientes mastectomizadas, aborda o acompanhamento à mulher em todas as fases da doença, desde a visita pré-operatória até a recuperação cirúrgica. Para o estabelecimento desses cuidados é essencial o conhecimento da equipe de enfermagem da realidade dessa mulher principalmente no pós-operatório, possibilitando, por meio de apoio técnicocientífico, a melhor forma dessa mulher enfrentar a doença e ter uma melhor readaptação.

Desse modo, justifica-se a proposta do presente estudo, cuja contribuição original consiste em abordar aspectos relativos ao câncer de mama, assim como os cuidados necessários pós-mastectomia; na esperança de contribuir com uma melhor formação, sensibilização e instrumentalização da equipe de enfermagem em relação ao tema e, assim, promover uma assistência mais qualificada a essas mulheres.

Com base nesses pressupostos, este estudo teve como objetivo identificar, na literatura, os cuidados adotados pela equipe de enfermagem diante de clientes mastectomizadas.

\section{MATERIAL E MÉTODOS}

Para realização do estudo, utilizou-se o método de pesquisa bibliográfica, que segundo Fonseca (2002, p. 32):

É feita a partir do levantamento de referências teóricas já analisadas, e publicadas por meios escritos e eletrônicos, como livros, artigos científicos, páginas de web sites. [...] Permite ao pesquisador conhecer o que já se estudou sobre o assunto. Existem [...] pesquisas científicas que se baseiam unicamente na pesquisa bibliográfica procurando referências teóricas publicadas com o objetivo de recolher informações ou conhecimentos prévios sobre o problema a respeito do qual se procura a resposta.

Procedeu-se o levantamento eletrônico por meio do portal de Pesquisa da Biblioteca Virtual em Saúde (BVS), nas bases de dados: Medline, Lilacs, Ibecs, Scielo, BDEnf, Biblioteca Cochrane, entre outras bases desse portal.

Como critérios de inclusão foram considerados pesquisas que abordam o tema cuidados adotados pela equipe de enfermagem diante de clientes mastectomizadas, no idioma português e espanhol com texto disponível. No período de 2009 a 2013. Não houve restrição quanto ao desenho de estudo. Os descritores escolhidos de acordo com a lista do DeCS/MeSH foram: enfermagem, cuidados de enfermagem, mastectomia, neoplasias da mama, enfrentamento, reabilitação, auto-cuidado.

Foram excluídos desse estudo artigos que não atenderam aos critérios de inclusão. 
Para análise e síntese do material foram aplicados os seguintes procedimentos: leitura exploratória do material para saber o conteúdo dos artigos; leitura seletiva, que constituiu na seleção do material quanto à sua importância e característica para o estudo; leitura crítica que buscará o tema em questão; tabulação dos artigos com a identificação do objeto de estudo, e posteriormente análise descritiva.

\section{RESULTADOS}

Os documentos coletados na busca bibliográfica foram avaliados quanto à condição de inclusão e exclusão, com base nos critérios de elegibilidade.

No total da busca eletrônica obteve-se 30 artigos; dispostos nas seguintes bases: Lilacs (23); Medline (4) e IBECS (Espanha) (3); somente 7 preencheram os critérios de inclusão para a revisão. Os demais foram excluídos por não estarem dentro dos critérios de inclusão.

Após a leitura exploratória dos mesmos, foi possível identificar artigos sobre cuidados adotados pela equipe de enfermagem diante de clientes mastectomizadas.

Quadro 1 - Distribuição de referências bibliográficas, sobre cuidados adotados pela equipe de enfermagem diante de clientes mastectomizadas, no período de 2009 a 2013. 
Revista Científica Multidisciplinar Núcleo do Conhecimento - RC: 12238 - ISSN: 2448-0959

https://www.nucleodoconhecimento.com.br/saude/mastectomizadas

\begin{tabular}{|c|c|c|c|c|}
\hline $\begin{array}{l}\text { Autor / Título } / \\
\text { Ano }\end{array}$ & Objetivo & Metodologia & Cuidados de & Conclusão \\
\hline $\begin{array}{l}\text { ALVES et al. } \\
\text { Cuidados de } \\
\text { enfermagem no } \\
\text { pré-operatório e } \\
\text { reabilitação de } \\
\text { mastectomia: } \\
\text { revisão } \\
\text { narrativa da } \\
\text { literatura. } 2010 \text {. }\end{array}$ & $\begin{array}{l}\text { Revisar a } \\
\text { produção } \\
\text { cientifica } \\
\text { referente aos } \\
\text { cuidados de } \\
\text { enfermagem no } \\
\text { periodo pré- } \\
\text { operatório e de } \\
\text { reabilitação de } \\
\text { mastectomia. }\end{array}$ & $\begin{array}{l}\text { Pesquisa } \\
\text { bibliográfica } \\
\text { realizada nas } \\
\text { bases de dados } \\
\text { Lilacs e Scielo. } \\
\text { Publicados } \\
\text { entre os anos } \\
\text { de } 1998 \text { a } 2008 \text {. } \\
\text { Foram } \\
\text { analisados } 18 \\
\text { artigos } \\
\text { focalizados nas } \\
\text { seguintes } \\
\text { categorias: } \\
\text { Cuidados de } \\
\text { enfermagem no } \\
\text { pré-operatório } \\
\text { da mastectomia } \\
\text { e O papel da } \\
\text { Enfermagem na } \\
\text { reabilitação da } \\
\text { mulher } \\
\text { mastectomizada } \\
\text { - }\end{array}$ & $\begin{array}{l}\text { Observou-se que os } \\
\text { cuidados de } \\
\text { enfermagem nos } \\
\text { dois periodos são } \\
\text { fundamentais para } \\
\text { um tratamento mais } \\
\text { humanizado. }\end{array}$ & $\begin{array}{l}\text { As orientações } \\
\text { recebidas pelas } \\
\text { mulheres no } \\
\text { periodo pré- } \\
\text { operatório e de } \\
\text { reabilitação são } \\
\text { precárias, o que vai } \\
\text { de encontro ao que } \\
\text { se espera, pois o } \\
\text { profissional de } \\
\text { saúde que se } \\
\text { propõe a trabalhar } \\
\text { com mulheres com } \\
\text { câncer de mama } \\
\text { deve prestar } \\
\text { assistência que } \\
\text { congregue técnica, } \\
\text { ciência e } \\
\text { humanização, } \\
\text { fornecendo todas as } \\
\text { informações e } \\
\text { orientações, } \\
\text { respeitando as } \\
\text { necessidades e o } \\
\text { nivel de } \\
\text { entendimento } \\
\text { dessas mulheres, } \\
\text { reabilitando-as para } \\
\text { o autocuidado. }\end{array}$ \\
\hline
\end{tabular}

\begin{tabular}{|c|c|c|c|c|}
\hline $\begin{array}{l}\text { MOURÃO et al. } \\
\text { Evidências para } \\
\text { o cuidado da } \\
\text { mulher } \\
\text { mastectomizad } \\
\text { a no } \\
\text { perioperatório. } \\
2013 \text {. }\end{array}$ & $\begin{array}{l}\text { Avaliar as } \\
\text { evidências } \\
\text { disponiveis na } \\
\text { literatura sobre os } \\
\text { tipos de cuidados } \\
\text { prestados à } \\
\text { mulher submetida } \\
\text { à mastectomia no } \\
\text { perioperatório. }\end{array}$ & $\begin{array}{l}\text { Revisão } \\
\text { integrativa da } \\
\text { literatura } \\
\text { realizada nas } \\
\text { bases de dados } \\
\text { MEDLINE, } \\
\text { CINAHL, } \\
\text { LILACS e portal } \\
\text { de periódicos } \\
\text { SciELO. } \\
\text { Publicados de } \\
2000 \text { a } 2011 . \text { A } \\
\text { amostra } \\
\text { constituiu-se de } \\
7 \text { artigos. }\end{array}$ & $\begin{array}{l}\text { Observou-se } \\
\text { preocupação por } \\
\text { parte dos } \\
\text { profissionais em } \\
\text { minimizar / prevenir } \\
\text { a dor pré, intra e } \\
\text { pós-operatória. }\end{array}$ & $\begin{array}{l}\text { A enfermagem deve } \\
\text { ater-se tanto à } \\
\text { atualização dos } \\
\text { tratamentos } \\
\text { farmacológicos no } \\
\text { manejo da dor } \\
\text { quanto ao } \\
\text { desenvolvimento de } \\
\text { futuras pesquisas } \\
\text { relacionadas ao } \\
\text { cuidado de } \\
\text { enfermagem no } \\
\text { período } \\
\text { perioperatório de } \\
\text { mastectomia. }\end{array}$ \\
\hline
\end{tabular}


Revista Científica Multidisciplinar Núcleo do Conhecimento - RC: 12238 - ISSN: 2448-0959

https://www.nucleodoconhecimento.com.br/saude/mastectomizadas

\begin{tabular}{|c|c|c|c|c|}
\hline $\begin{array}{l}\text { OLIVEIRA et al. } \\
\text { Sistematização } \\
\text { da assistência } \\
\text { de enfermagem } \\
\text { (SAE) às } \\
\text { mulheres } \\
\text { mastectomizad } \\
\text { as. } 2010 \text {. }\end{array}$ & $\begin{array}{l}\text { Utilizar a SAE às } \\
\text { mulheres } \\
\text { mastectomizadas }\end{array}$ & $\begin{array}{l}\text { Estudo } \\
\text { descritivo, } \\
\text { realizado em } \\
\text { uma instituição } \\
\text { especializada } \\
\text { em oncologia. }\end{array}$ & $\begin{array}{l}\text { Aplicação da SAE } \\
\text { às mulheres } \\
\text { mastectomizadas } \\
\text { com a verificação } \\
\text { dos principais } \\
\text { problemas de } \\
\text { enferm agem nessas } \\
\text { mulheres. Permitiu } \\
\text { estabelecer os } \\
\text { principais } \\
\text { diagnósticos de }\end{array}$ & $\begin{array}{l}\text { A análise } \\
\text { demonstrou que, } \\
\text { após a } \\
\text { mastectomia, as } \\
\text { mulheres } \\
\text { apresentam } \\
\text { algumas limitações, } \\
\text { mas enfrentam de } \\
\text { maneira satisfatória } \\
\text { a mudança } \\
\text { corporal. }\end{array}$ \\
\hline & & & $\begin{array}{l}\text { enfermagem pela } \\
\text { classificação de } \\
\text { NANDA e } \\
\text { determinar as ações } \\
\text { de enfermagem } \\
\text { para mulheres após } \\
\text { a realização de } \\
\text { mastectomia. }\end{array}$ & \\
\hline $\begin{array}{l}\text { MENDES; } \\
\text { LINDOLPHO; } \\
\text { LEITE. A } \\
\text { Assistência da } \\
\text { enfermeira na } \\
\text { visão de } \\
\text { mulheres } \\
\text { mastectomizad } \\
\text { as. } 2012 \text {. }\end{array}$ & $\begin{array}{l}\text { Identificar as } \\
\text { expectativas das } \\
\text { mulheres } \\
\text { mastectomizadas } \\
\text { em relação à } \\
\text { assistência da } \\
\text { enfermeira e } \\
\text { descrever como } \\
\text { essas mulheres } \\
\text { perceberam a } \\
\text { assistência que } \\
\text { lhes foi prestada. }\end{array}$ & $\begin{array}{l}\text { Pesquisa } \\
\text { descritiva do } \\
\text { tipo estudo de } \\
\text { caso, com } \\
\text { abordagem } \\
\text { qualitativa, } \\
\text { utilizando } \\
\text { entrevista } \\
\text { aberta com } 9 \\
\text { mulheres, } \\
\text { participantes de } \\
\text { um grupo de } \\
\text { apoio a } \\
\text { mulheres } \\
\text { mastectomizada } \\
\text { s, em Niterói - } \\
\text { RJ - Brasil. }\end{array}$ & $\begin{array}{l}\text { Identificaram-se as } \\
\text { expectativas em } \\
\text { relação à } \\
\text { enfermeira: que } \\
\text { deverá ter } \\
\text { competência } \\
\text { técnica e } \\
\text { compreender o } \\
\text { momento } \\
\text { vivenciado pelas } \\
\text { mulheres. Sobre } \\
\text { sua atuação, } \\
\text { relataram que } \\
\text { esclareceu dúvidas, } \\
\text { foi essencial no } \\
\text { pós-operatório, } \\
\text { realizou } \\
\text { procedimentos } \\
\text { técnicos e deu } \\
\text { apoio emocional. }\end{array}$ & $\begin{array}{l}\text { Evidenciou-se que a } \\
\text { assistência de } \\
\text { enfermagem, tanto } \\
\text { relativa à } \\
\text { enfermeira quanto } \\
\text { aos outros da } \\
\text { equipe, se mostrava } \\
\text { de forma } \\
\text { diferenciada } \\
\text { conforme a } \\
\text { procedência da } \\
\text { instituição. Na } \\
\text { instituição } \\
\text { especializada, } \\
\text { enfermeira com } \\
\text { função clara e } \\
\text { definida; na } \\
\text { generalista, função } \\
\text { velada. }\end{array}$ \\
\hline
\end{tabular}




\begin{tabular}{|c|c|c|c|c|}
\hline $\begin{array}{l}\text { PEREIRA et al. } \\
\text { O adoecer e } \\
\text { sobreviver ao } \\
\text { câncer de } \\
\text { mama: a } \\
\text { vivência da } \\
\text { mulher } \\
\text { mastectomizad } \\
\text { a. } 2013 \text {. }\end{array}$ & $\begin{array}{l}\text { Conhecer a } \\
\text { vivência da } \\
\text { mulher } \\
\text { mastectomizada } \\
\text { frente ao adoecer } \\
\text { e sobreviver ao } \\
\text { câncer de mama }\end{array}$ & $\begin{array}{l}\text { Estudo } \\
\text { qualitativo } \\
\text { desenvolvido } \\
\text { com cinco } \\
\text { mulheres } \\
\text { sobreviventes } \\
\text { ao câncer de } \\
\text { mama, } \\
\text { mastectomizada } \\
\text { e com alto grau } \\
\text { de resiliência } \\
\text { atendidas na } \\
\text { Unidade de } \\
\text { Oncologia do } \\
\text { Hospital Escola } \\
\text { (UFPel) } \\
\text { Pelotas/RS. }\end{array}$ & $\begin{array}{l}\text { Avaliação das } \\
\text { necessidades e } \\
\text { construção de um } \\
\text { plano de cuidado } \\
\text { que valorize a } \\
\text { integralidade e } \\
\text { individualidade da } \\
\text { mastectomizada. } \\
\text { Promover } \\
\text { articulação com as } \\
\text { demais areas da } \\
\text { saúde, com ações } \\
\text { que contribuam } \\
\text { para uma vida de } \\
\text { qualidade bem } \\
\text { como para sua } \\
\text { reinserção social. }\end{array}$ & $\begin{array}{l}\text { Após os } \\
\text { tratamentos, a vida } \\
\text { das informantes se } \\
\text { modificou, elas } \\
\text { passaram a avaliar } \\
\text { a maneira como } \\
\text { viviam até então, e } \\
\text { a buscar novas } \\
\text { formas de viver } \\
\text { condizente com as } \\
\text { consequências } \\
\text { deixadas pela } \\
\text { doença, procurando } \\
\text { caminhos } \\
\text { alternativos que } \\
\text { proporcionassem } \\
\text { uma vida com } \\
\text { qualidade para além } \\
\text { do câncer. }\end{array}$ \\
\hline $\begin{array}{l}\text { SANTOS et al. } \\
\text { Comunicação } \\
\text { terapêutica no } \\
\text { cuidado pré- } \\
\text { operatório de } \\
\text { mastectomia. } \\
2010 \text {. }\end{array}$ & $\begin{array}{l}\text { Refletir sobre o } \\
\text { desenvolvimento } \\
\text { da comunicação } \\
\text { terapêutica do } \\
\text { enfermeiro na } \\
\text { unidade de } \\
\text { internação pré- } \\
\text { operatória de } \\
\text { mulheres } \\
\text { mastectomizadas }\end{array}$ & $\begin{array}{l}\text { Relato de } \\
\text { experiência } \\
\text { sobre a prática } \\
\text { docente- } \\
\text { assistencial em } \\
\text { hospital de } \\
\text { oncologia. }\end{array}$ & $\begin{array}{l}\text { O exercício da } \\
\text { comunicação } \\
\text { terapêutica } \\
\text { configura-se uma } \\
\text { prática favorável, } \\
\text { porquanto } \\
\text { estabelece o } \\
\text { vínculo enfermeiro- } \\
\text { paciente, sendo a } \\
\text { paciente produtora } \\
\text { do próprio cuidado. } \\
\text { O enfermeiro } \\
\text { assume } \\
\text { compromisso de } \\
\text { preestabelecer os } \\
\text { cuidados de } \\
\text { enfermagem em } \\
\text { parceria, de forma a } \\
\text { atender às } \\
\text { necessidades da } \\
\text { paciente, e com } \\
\text { vistas, } \\
\text { principalmente, à } \\
\text { autonomia do } \\
\text { cuidado. }\end{array}$ & $\begin{array}{l}\text { A equipe de } \\
\text { enfermagem exerce } \\
\text { papel fundamental } \\
\text { no processo de } \\
\text { recuperação da } \\
\text { mulher } \\
\text { mastectomizada, } \\
\text { uma vez que esta } \\
\text { promove suporte } \\
\text { emocional e } \\
\text { informativo sobre os } \\
\text { cuidados } \\
\text { necessários à } \\
\text { reabilitação pós- } \\
\text { mastectomia, além } \\
\text { de proporcionar } \\
\text { tranquilidade e } \\
\text { conforto perante os } \\
\text { sentimentos e as } \\
\text { expectativas. Cabe, } \\
\text { ainda, ao } \\
\text { enfermeiro orientar } \\
\text { para a alta e } \\
\text { direcionar a mulher } \\
\text { para o autocuidado } \\
\text { e para grupos que } \\
\text { promovam a } \\
\text { reintegração à } \\
\text { sociedade e a seu } \\
\text { cotidiano familiar. }\end{array}$ \\
\hline
\end{tabular}




\begin{tabular}{|c|c|c|c|c|}
\hline SILVA et al. & Identificar as & Estudo & A enfermagem pode & Entende-se que a \\
\hline $\begin{array}{l}\text { Representaçõe } \\
\text { s sociais de } \\
\text { mulheres }\end{array}$ & $\begin{array}{l}\text { representações } \\
\text { sociais de } \\
\text { mulheres }\end{array}$ & $\begin{array}{l}\text { qualitativo } \\
\text { segundo o } \\
\text { referencial }\end{array}$ & $\begin{array}{l}\text { contribuir para a } \\
\text { prevenção e a } \\
\text { promoção da }\end{array}$ & $\begin{array}{l}\text { enfermagem tem } \\
\text { papel relevante na } \\
\text { promoção da }\end{array}$ \\
\hline $\begin{array}{l}\text { mastectomizad } \\
\text { as e suas } \\
\text { implicações } \\
\text { para o }\end{array}$ & $\begin{array}{l}\text { mastectomizadas } \\
\text { sobre a mama e } \\
\text { analisar as } \\
\text { implicações }\end{array}$ & $\begin{array}{l}\text { Teoria das } \\
\text { Representações } \\
\text { Sociais. }\end{array}$ & $\begin{array}{l}\text { saúde, prestando } \\
\text { um cuidado de } \\
\text { forma holistica. } \\
\text { Portanto, o apoio, o }\end{array}$ & $\begin{array}{l}\text { saúde, por meio da } \\
\text { realização de ações } \\
\text { educativas com } \\
\text { essas mulheres, }\end{array}$ \\
\hline $\begin{array}{l}\text { autocuidado. } \\
2010 \text {. }\end{array}$ & $\begin{array}{l}\text { dessas } \\
\text { representações } \\
\text { sociais no }\end{array}$ & & $\begin{array}{l}\text { carinho, a atenção e } \\
\text { o suporte emocional } \\
\text { são essenciais para }\end{array}$ & $\begin{array}{l}\text { sensibilizando-as } \\
\text { quanto à } \\
\text { importância do }\end{array}$ \\
\hline & autocuidado. & & $\begin{array}{l}\text { o cuidado às } \\
\text { mulheres } \\
\text { mastectomizadas, }\end{array}$ & $\begin{array}{l}\text { cuidado de si por } \\
\text { meio da realização } \\
\text { do autoexame como }\end{array}$ \\
\hline & & & $\begin{array}{l}\text { considerando que } \\
\text { proporcionam um } \\
\text { melhor } \\
\text { enfrentamento da } \\
\text { doença e superação } \\
\text { desses momentos }\end{array}$ & $\begin{array}{l}\text { forma de permitir a } \\
\text { detecção precoce } \\
\text { do câncer de } \\
\text { mama, reduzindo } \\
\text { assim os danos que } \\
\text { podem advir em sua }\end{array}$ \\
\hline & & & $\begin{array}{l}\text { dificeis de sua } \\
\text { vivência. }\end{array}$ & consequência. \\
\hline
\end{tabular}

Fonte: Moreira, Santos e Azevedo, 2014.

\section{DISCUSSÃO}

O Quadro 1 mostra dados da distribuição dos estudos incluídos na pesquisa de acordo com: autores, título, ano de publicação, objetivo, metodologia, cuidados de enfermagem adotados diante de clientes mastectomizadas e a conclusão.

Durante o período de 2009 a 2013, o ano que apresentou um maior número de trabalhos publicados disponíveis eletronicamente com a temática em foco foi o de 2010 (4 artigos), seguido do ano de 2013 (2) e 2012 (1). Os trabalhos foram resgatados na base de dados Lilacs (7 artigos), enquanto o país de origem das pesquisas selecionadas foi o Brasil. Isso pode estar relacionado ao fato de ter-se definido na metodologia busca de material o idioma português e espanhol. Ressalta-se que não foi levado em consideração o tipo de estudo.

É sabido que a mastectomia é um procedimento cirúrgico agressivo acompanhado de consequências traumatizantes nas experiências de vida e saúde da mulher, portanto a assistência de enfermagem neste período é fundamental.

Dos artigos selecionados 100\% relatam a importância da mulher receber informações a respeito dos cuidados no período perioperatório que se divide em pré-operatório, trans-operatório e pós-operatório. Após a cirurgia, faz-se necessário, por meio da equipe de enfermagem, fornecer orientações sobre as diferentes etapas de recuperação, além de esclarecimentos sobre outros tratamentos como quimioterapia, radioterapia e hormonioterapia (ALVES et al., 2011; MOURÃO et al., 2013; OLIVEIRA, 2010; MENDES; LINDOLPHO; LEITE, 2012; PEREIRA et al., 2013; SANTOS et al., 2010; SILVA et al., 2010). 
Para Alves et al. (2011) essas informações e orientações repassadas são consideradas imprescindíveis para diminuir a ansiedade e o medo frente ao diagnóstico e tratamento. Assim, a importância da informação sobre a doença, tratamento e suas consequências são fundamentais.

Corroborando Santos et al. (2010) dizem que a equipe de enfermagem tem um importante papel pois deve estabelecer com a mulher mastectomizada uma comunicação terapêutica proporcionando cuidado de enfermagem que, por sua vez, atenda as expectativas e necessidades dessas mulheres, assegurando conforto físico, emocional e espiritual.

Mendes, Lindolpho e Leite (2012, p. 431) referem que a enfermagem deve atuar de forma a "preservar a autonomia e a dignidade' das mulheres mastectomizadas, protegendo sua integridade física e psíquica”.

Observou-se ainda que $90 \%$ dos artigos abordam o cuidado à mulher com diagnóstico de câncer de mama e provável evolução a mastectomia.

A equipe de enfermagem deve considerar que para o cuidado ser eficaz, faz-se necessário um processo interativo, em que o profissional aplique além da habilidade técnica, conhecimentos e, sobretudo, humanização com o indivíduo a ser cuidado em todos os períodos do tratamento (MOURÃO et al., 2013).

Desta forma, a equipe de enfermagem deve conhecer as necessidades específicas de cada uma, avaliar suas necessidades e construir um plano de cuidado que valorize sua integralidade e individualidade (MOURÃO et al., 2013; PEREIRA et al., 2013).

Para Mendes, Lindolpho e Leite (2012) a atuação da enfermagem nos cuidados do dia-a-dia deve se refletir numa assistência de enfermagem de qualidade que aponta para o autocuidado, objetivando a melhoria da qualidade de vida da paciente e, possibilitando também, um reconhecimento do profissional ao estabelecer uma boa relação enfermeiro-paciente.

Ainda, segundo os autores citados, torna-se imprescindível que a enfermagem procure sempre perspectivas diferenciadas no cuidar à paciente oncológica. É importante que a enfermagem esteja atenta às mudanças e novidades nos tratamentos a fim de oferecer uma assistência global, livre de mitos e tabus. Além disso, é necessário ressaltar a necessidade de elaboração de protocolos assistenciais direcionados à assistência a esta mulher, levando em consideração as diferenças regionais e socioculturais.

Alves et al. (2011) chamam a atenção que para a recuperação destas mulheres, além da atuação profissional, é fundamental o apoio dado pela família e rede social, uma vez que as mudanças ocorridas após o tratamento da doença são significativas e transformadoras. Há necessidade de apoio por parte de pessoas próximas, como esposo, filhos e amigos.

Para alcançar este objetivo, torna-se necessário o desenvolvimento pela equipe de enfermagem de ações educativas que ajudem as pacientes e seus cuidadores a adquirirem conhecimento e habilidades sobre os diversos aspectos do seu autocuidado (ALVES et al., 2011).

Silva et al. (2010) afirmam que as ações de enfermagem têm fundamental importância nas atividades grupais com as mulheres mastectomizadas, no sentido de minimizar os conflitos identificados, estimulando o autocuidado e valorizando cada participante como um ser único. É importante o apoio e a 
orientação não somente para as mulheres mastectomizadas, mas também para a família, que é parte essencial no tratamento, pois, se o suporte emocional for de qualidade, será bastante significativo na recuperação da mulher, ajudando-a na melhora da autoestima e consequentemente contribuindo na recuperação da autoimagem.

Outro aspecto importante abordado em $40 \%$ dos artigos selecionados é o impacto psicológico, social e físico bem como a aceitação à mutilação. Neste contexto, Pereira et al. (2013) afirmam que o câncer está entre as doenças que mais provocam medo e preocupações, criando uma imagem estigmatizada de sofrimento, aversão e morte.

Segundo Silva et al. (2010) a mulher acometida do câncer de mama vivencia, em sua trajetória, inúmeras situações. Essas, em geral, referem-se a sua integridade biopsicossocial, a incerteza do sucesso do tratamento, a possibilidade da recorrência e a morte. Aceitar a sua nova condição e adaptar-se à nova imagem de seu corpo exige um esforço muito grande para o qual não estão preparadas.

Fica evidente que as alterações corporais decorrentes da mastectomia total ou parcial tem grande significado para a vida destas mulheres, principalmente por se tratarem de mudanças permanentes e esteticamente fora dos padrões impostos pela sociedade (PEREIRA et al., 2013).

A iminência da retirada da mama e a desinformação, possui um peso negativo, o que favorece, consideravelmente, a vulnerabilidade, a fragilidade e, até mesmo a falta de apoio a elas no vivenciar deste momento.

Portanto, a assistência de enfermagem deve incluir medidas para prevenir ou minimizar a angústia referida pela mulher após o diagnóstico de câncer de mama e posterior tratamento, e que incluem a mobilização de suporte social disponível, a ênfase nas questões psicossociais e o fornecimento de informações a mulher, no sentido de facilitar o enfrentamento efetivo da doença e procedimento cirúrgico, restaurando o senso de normalidade e independência física (ALVES et al., 2011).

\section{CONCLUSÃO}

A assistência de enfermagem em oncologia evoluiu muito desde seu aparecimento como especialidade e a literatura aponta e preconiza a importância da enfermagem no apoio a paciente oncológica e a sua família, nas várias fases de sua doença: prevenção primária e secundária, tratamento, reabilitação e doença avançada.

Assim os artigos destacam o papel educador do enfermeiro na assistência prestada a estas mulheres, já que a falta ou imprecisão nas informações prestadas favorece a ocorrência de complicações. O enfermeiro é o profissional preparado para desempenhar este papel de educador, fornecendo informações para a paciente e seus familiares, o que está destacado no Código de Ética dos Profissionais de Enfermagem Brasileiros.

Além disso, a enfermagem deve promover a articulação com as demais áreas da saúde, com ações que contribuam para uma vida de qualidade bem como para sua reinserção social.

\section{REFERÊNCIAS}


ALVES, P. C. et al. Cuidados de enfermagem no pré-operatório e reabilitação de mastectomia: revisão narrativa da literatura. Rev. bras. enferm., Brasília, v. 64, n. 4, ago. 2011.

ANGERAMI-CAMON, V. A.; GASPAR, K. C. Psicologia e câncer. São Paulo: Casa do Psicólogo, 2013.

AZEVEDO, R. F.; LOPES, R. L. M. Vivência do diagnóstico de câncer de mama e de mastectomia radical: percepção do corpo feminino a partir da fenomenologia. Online Brazilian Journal of Nursing, Niterói (RJ), v. 5, n.1, Apr. 2006.

BARRETO, R. A. S. et al. As necessidades de informação de mulheres mastectomizadas subsidiando a assistência de enfermagem. Rev. Eletr. Enf. [Internet]. v. 10, n. 1, p. 110-23, 2008.

BITTENCOURT, J. F. V.; CADETE, M. M.mastectomizada: esclarecimentos e orientações. 420-3, 2002.

Vivências da mulher a ser Rev Bras Enferm. v. 55, n. 4, p. FONSECA, J. J. S. Metodologia da pesquisa científica. Fortaleza: UEC, 2002.

INSTITUTO NACIONAL DE CÂNCER JOSÉ ALENCAR GOMES DA SILVA. Coordenação Geral de Ações Estratégicas. Coordenação de Educação. Incidência de câncer no Brasil. Rio de Janeiro, 2014.

MENDES, A. B. P.; LINDOLPHO, M. C.; LEITE, A. P. A assistência da enfermeira na visão de mulheres mastectomizadas. Enfermería global, n. 26, abr. 2012.

MOURÃO, C. M. L. et al. Evidências para o cuidado da mulher mastectomizada no perioperatório. Rev. RENE, v. 14, n. 6, p. 1232-40, nov.-dez. 2013.

MOURÃO, C. M. L. Evidências para o cuidado perioperatório da mulher mastectomizada: revisão integrativa da literatura. 2011. 70f. Dissertação (Mestrado) Universidade Federal do Ceará, Programa de Pós-graduação em Enfermagem. Fortaleza, Ceará, 2011.

OLIVEIRA, S. K. P. et al. Sistematização da assistência de enfermagem às mulheres mastectomizadas. Cogitare Enferm., v. 15,n. 2, p. 319-26, Abr/Jun. 2010.

PEREIRA, C. M. et al. O adoecer e sobreviver ao câncer de mama: a vivência da mulher mastectomizada. R. pesq.: cuid. fundam. online, v. 5, n. 2, p. 3837-46.abr./jun. 2013.

SANTOS, M. C. L. et al. Comunicação terapêutica no cuidado pré-operatório de mastectomia. Rev. bras. enferm., Brasília, v. 63, n. 4, ago. 2010.

SILVA, S. É. D. et al. Representações sociais de mulheres mastectomizadas e suas implicações para o autocuidado. Rev. bras. enferm., Brasília, v. 63, n. 5, out. 2010.

SMELTZER, S. C.; BARE, B. G. Brunner e Suddarth - Tratado de enfermagem medica-cirúrgica. 9. ed. Rio de Janeiro: Guanabara Koogan, 2002. 1813p. 
SOUZA, M. M. et al . Taxa de mortalidade por neoplasia maligna de mama em mulheres residentes da região Carbonífera Catarinense no período de 1980 a 2009. Cad. saúde colet., Rio de Janeir, v. 21, n. 4, 2013.

${ }^{[1]}$ Enfermeira graduada pela Faculdade Metropolitana da Amazonia (FAMAZ).

${ }^{[2]}$ Enfermeira graduada pela Faculdade Metropolitana da Amazonia (FAMAZ).

${ }^{[3]}$ Psicóloga. Mestre em Teoria e Pesquisa do Comportamento. Doutoranda em Doenças Tropicais pelo Núcleo de Medicina Tropical da UFPA (NMT-UFPA). Docente da Universidade do Estado do Pará UEPA

${ }^{[4]}$ Doutora em Psicanálise Clínica, Pesquisadora pelo Centro de Pesquisa e Estudos Avançados.

${ }^{[5]}$ Registered Nurse e Bachelors in Nursing Science. USA - California

[6] Biólogo. Doutor em Medicina/Doenças Tropicais. Docente e Pesquisador na Universidade Federal do Pará - UFPA. Pesquisador no Laboratório de Toxicologia Humana e Ambiental e no Laboratório de Estresse Oxidativo do Núcleo de Medicina Tropical da UFPA (NMT-UFPA).

\section{PUBLIQUE SEU ARTIGO CIENTÍFICO EM:}

https://www.nucleodoconhecimento.com.br/enviar-artigo-cientifico-para-submissao 